\title{
Thermal Stability of Bent-Core Liquid Crystals Doped with Magnetic Nanoparticles
}

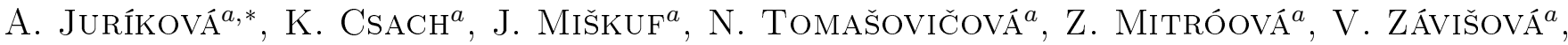

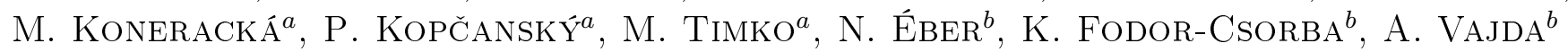 \\ ${ }^{a}$ Institute of Experimental Physics, Slovak Academy of Sciences, Watsonova 47, 04001 Košice, Slovakia \\ ${ }^{b}$ Institute for Solid State Physics and Optics, Wigner Research Centre for Physics, Hungarian Academy of Sciences, \\ H-1525 Budapest, P. O. Box 49, Hungary
}

\begin{abstract}
In the work phase transitions in bent-core liquid crystals were studied using differential scanning calorimetry. For the binary mixture of bent-core molecules with $50 \mathrm{wt} \%$ of rod-shaped compound, the nematic to smectic transition occured below $40{ }^{\circ} \mathrm{C}$ and the crystallization temperature shifted to sub-ambient temperatures. The influence of doping of the bent-core liquid crystals with magnetic nanoparticles on the kinetics of observed phase transitions was studied. The phase transition temperatures were shifted depending on the nanoparticle type and changed with varying cooling rate for all studied liquid crystal samples.
\end{abstract}

DOI: 10.12693/APhysPolA.127.638

PACS: 61.30.-v, 64.70.mj, 65.80.-g

\section{Introduction}

Liquid crystals are anisotropic fluids with long-range orientational order, which combine the fluidity of ordinary liquids with the interesting electrical and optical properties of crystalline solids. Banana-shaped (or bentcore) mesogens represent a novel class of thermotropic liquid crystals (LCs) which have become targets of extensive studies in the last decade [1-3]. Pure bent-core compounds usually have liquid crystalline phases much above room temperature which limits their usability for many applications. However, mixtures of suitable bentcore and rod-shaped molecules can form liquid crystalline phase at room temperature and thus can be useful in possible practical applications [4-6]. Morever, doping liquid crystals with magnetic particles can modify the phase transition temperatures and increase the sensitivity to external magnetic field $[7,8]$.

Differential scanning calorimetry (DSC) is a powerful technique that complements optical methods in the study of phase transitions of liquid crystals [9]. In this work, kinetics of phase transitions in pure banana and rod-shaped liquid crystals and in their binary mixture were studied using the DSC method. The influence of doping by different types of magnetic nanoparticles on phase transitions in the liquid crystal samples was also investigated.

\section{Experimental}

The banana-shaped 4,6-dichloro-1,3-phenylenebis [4'-(9-decen-1-yloxy)-1,1'-biphenyl] 4-carboxylate (10DClPBBC) and the rod-shaped 4-n-octyloxyphenyl

\footnotetext{
* corresponding author; e-mail: akasard@saske.sk
}

4-n-hexyloxybenzoate (6008) liquid crystals and their 50:50 wt $\%$ mixture were used in the experiment. They were doped with different types of magnetic nanoparticles (spherical and rodlike magnetite nanoparticles and magnetite labeled single wall carbon nanotubes (SWCNT $\left./ \mathrm{Fe}_{3} \mathrm{O}_{4}\right)$ ) at weight concentrations of about $7.5-8.5 \times 10^{-4}$. The spherical magnetic particles were prepared by co-precipitation of $\mathrm{Fe}^{2+}$ and $\mathrm{Fe}^{3+}$ salts by $\mathrm{NH}_{4} \mathrm{OH}$ at $60^{\circ} \mathrm{C}$. Magnetic rodlike particles were synthesized through hydrolysis of $\mathrm{FeCl}_{3}$ and $\mathrm{FeSO}_{4}$ solutions containing urea. Single-walled carbon nanotubes were labeled with magnetite by precipitation method in nitrogen atmosphere at $60^{\circ} \mathrm{C}$. DSC experiments were performed using a Perkin Elmer DSC 8000 apparatus.

\section{Results and discussion}

Figure 1 shows typical DSC traces indicating the occurence phase transitions obtained, for the pure bananashaped (B) and the rod-shaped (R) liquid crystals, as well as for their mixture of $\mathrm{B}: \mathrm{R}=50: 50$ weight ratio ( wt\%) upon a heating/cooling cycle at the rate of $10 \mathrm{~K} / \mathrm{min}$.

The presence of crystal $(\mathrm{Cr})$ to nematic $(\mathrm{N})$ and nematic to isotropic (I) transitions was confirmed for all samples during heating. The temperatures of the corresponding peaks upon heating and cooling do not coincide: they differ each other only slightly for the I-N transition whereas the crystallization temperatures are substantially different from the melting temperatures. In the rod-shaped liquid crystal sample a monotropic nematic to smectic $(\mathrm{SmC})$ transition appeared at the temperature of about $45^{\circ} \mathrm{C}$. The binary mixture with $50 \mathrm{wt} \%$ rodshaped compound exhibited the same N-SmC transition, however below $40^{\circ} \mathrm{C}$ and, in addition, the crystallization temperature was shifted to sub-ambient temperature of about $15^{\circ} \mathrm{C}$. 


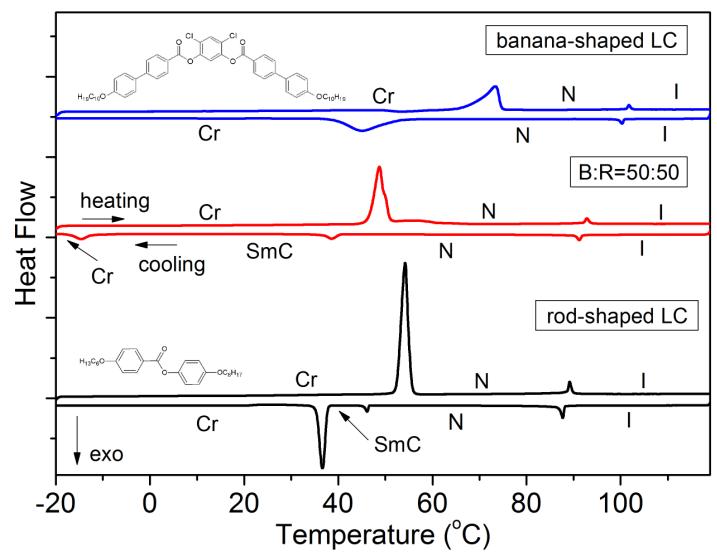

Fig. 1. DSC traces obtained for pure banana (B) and pure rod-shaped (R) LCs and for their mixture of 50:50 wt\% upon a heating/cooling cycle and the structural formulae of the tested compounds.
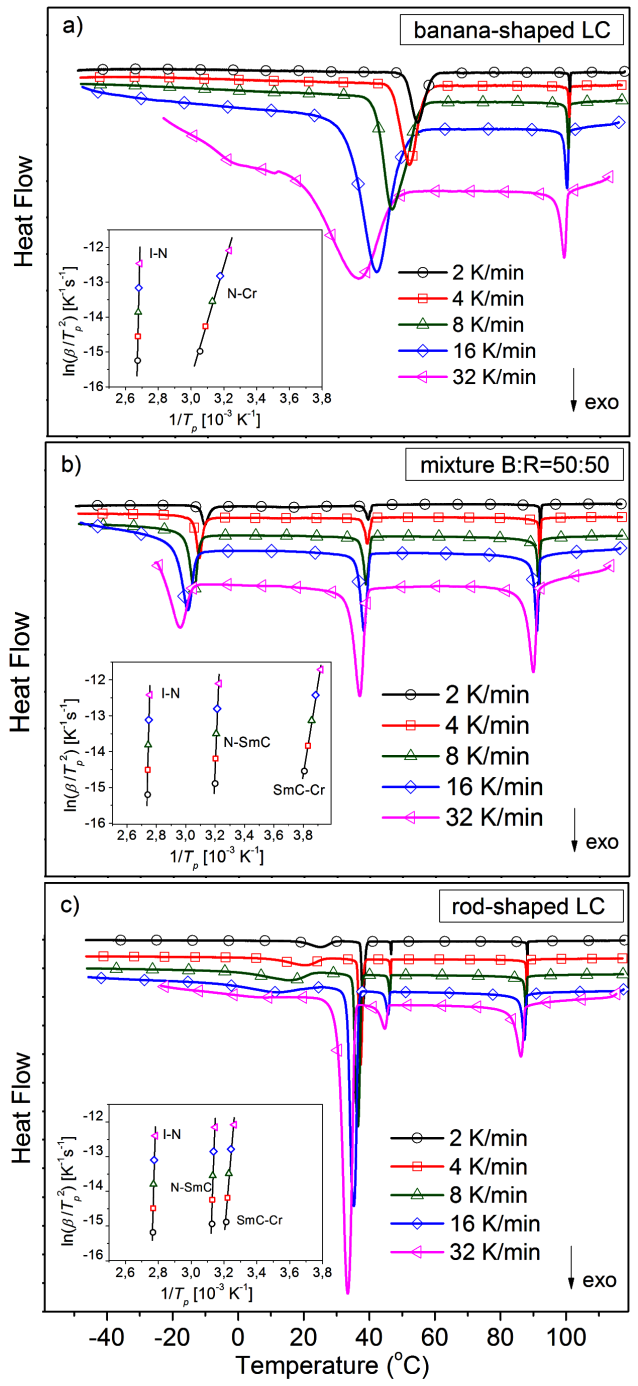

Fig. 2. DSC traces obtained during cooling cycles for the samples of a) pure banana-shaped LC, b) mixture of banana and rod-shaped LC with 50:50 wt\% ratio and c) pure rod-shaped LC. Insets show the corresponding Kissinger plots for the individual phase transition peaks.

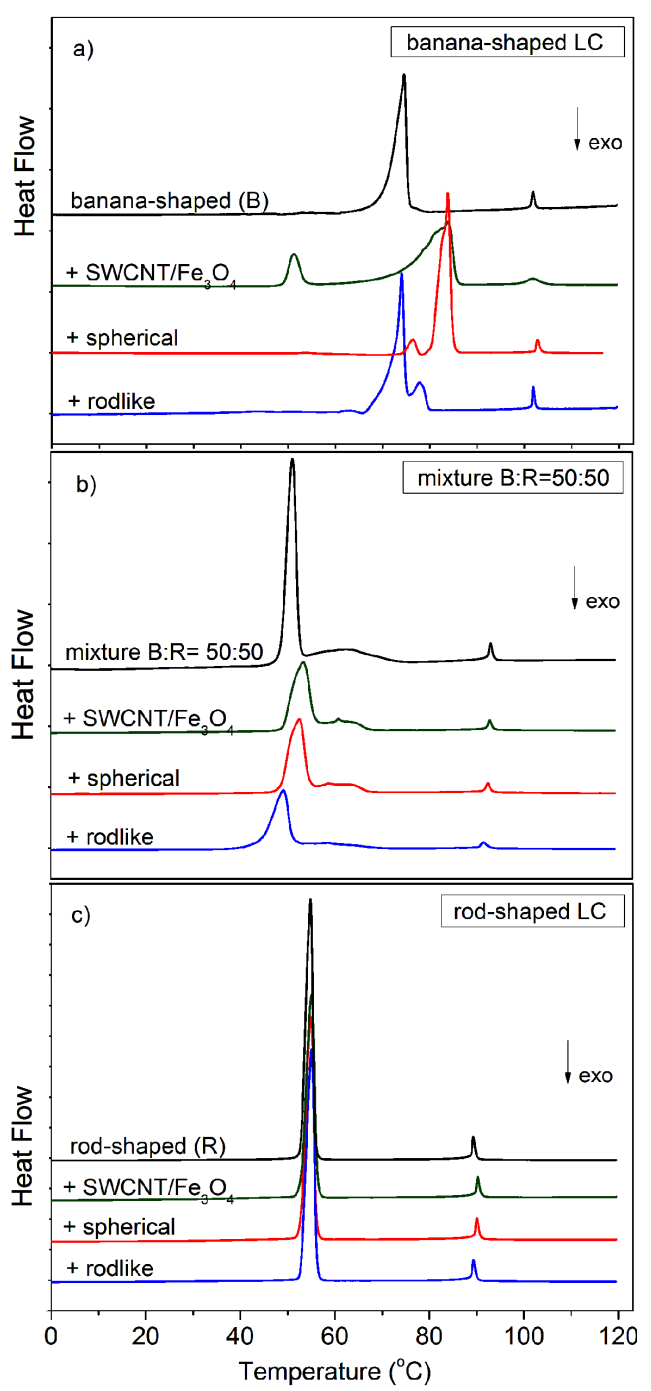

Fig. 3. Influence of doping a) the banana-shaped LC, b) the mixture of banana and rod-shaped LCs and c) the rod-shaped $\mathrm{LC}$ with $\mathrm{SWCNT} / \mathrm{Fe}_{3} \mathrm{O}_{4}$, spherical and rodlike magnetic particles. DSC were recorded in heating.

The width of the DSC peaks depends on the type of the phase transition and varies with the shape of the LC molecules. The nematic-isotropic transition peaks are narrow, but the peaks corresponding to the crystallization are wider and depend much more on the shape of the LCs.

Our results obtained from the DSC measurements are in good agreement with the ones obtained from polarizing microscopy measurements by Nair et al. [4].

Study of the kinetics of the phase transitions in the pure banana and rod-shaped LCs and in their mixture was also carried out by DSC analysis. The traces obtained during subsequent cooling runs starting from the temperature of $120^{\circ} \mathrm{C}$ at five different rates $\beta$ (ranging from 2 to $32 \mathrm{~K} / \mathrm{min}$ ) can be seen in Fig. 2. Insets show Kissinger plots for the individual phase transition peaks [9]. Activation energies $E_{a}$, together with the char- 
TABLE

Phase transition temperatures and the corresponding activation energies, determined from DSC measurements.

\begin{tabular}{|c|c|c|c|c|c|c|c|}
\hline \multirow{2}{*}{$\begin{array}{c}\text { phase } \\
\text { transition }\end{array}$} & \multirow[b]{2}{*}{$\begin{array}{c}\beta \\
{\left[\frac{\mathrm{K}}{\mathrm{min}}\right]} \\
\end{array}$} & \multicolumn{2}{|c|}{$\begin{array}{c}\text { banana } \\
\text { LC }\end{array}$} & \multicolumn{2}{|c|}{$\begin{array}{c}\text { mixture } \\
50: 50\end{array}$} & \multicolumn{2}{|c|}{$\operatorname{rod} \mathrm{LC}$} \\
\hline & & $\begin{array}{c}T_{p} \\
{\left[{ }^{\circ} \mathrm{C}\right]}\end{array}$ & $\begin{array}{c}E_{a} \\
{\left[\frac{\mathrm{kJ}}{\mathrm{mol}}\right]}\end{array}$ & $\begin{array}{c}T_{p} \\
{\left[{ }^{\circ} \mathrm{C}\right]} \\
\end{array}$ & $\begin{array}{c}E_{a} \\
{\left[\frac{\mathrm{kJ}}{\mathrm{mol}}\right]}\end{array}$ & $\begin{array}{c}T_{p} \\
{\left[{ }^{\circ} \mathrm{C}\right]} \\
\end{array}$ & $\begin{array}{c}E_{a} \\
{\left[\frac{\mathrm{kJ}}{\mathrm{mol}}\right]}\end{array}$ \\
\hline \multirow{5}{*}{$\mathrm{I}-\mathrm{N}$} & 32 & 99.0 & \multirow{5}{*}{$\begin{array}{l}1704.1 \\
\pm 329.1\end{array}$} & 89.7 & \multirow{5}{*}{$\begin{array}{l}1345.8 \\
\pm 282.0\end{array}$} & 86.2 & \multirow{5}{*}{$\begin{array}{l}1389.4 \\
\pm 300.1\end{array}$} \\
\hline & 16 & 99.9 & & 90.8 & & 87.3 & \\
\hline & 8 & 100.4 & & 91.3 & & 87.8 & \\
\hline & 4 & 100.6 & & 91.7 & & \begin{tabular}{|l|}
88.1 \\
\end{tabular} & \\
\hline & 2 & 100.8 & & 91.8 & & \begin{tabular}{|l|}
88.2 \\
\end{tabular} & \\
\hline \multirow{5}{*}{ N-SmC } & 32 & - & \multirow{5}{*}{ - } & 36.8 & \multirow{5}{*}{$\begin{array}{c}831.6 \\
\pm 150.4\end{array}$} & 44.7 & \multirow{5}{*}{$\begin{array}{l}1103.8 \\
\pm 236.3\end{array}$} \\
\hline & 16 & - & & 38.1 & & 45.7 & \\
\hline & 8 & - & & 38.7 & & 46.2 & \\
\hline & 4 & - & & 39.1 & & 46.5 & \\
\hline & 2 & - & & 39.4 & & 46.6 & \\
\hline \multirow{5}{*}{$\begin{array}{l}\mathrm{SmC}-\mathrm{Cr} \\
(\mathrm{N}-\mathrm{Cr})\end{array}$} & 32 & 36.1 & \multirow{5}{*}{$\begin{array}{l}132.8 \\
\pm 7.5\end{array}$} & -18.1 & \multirow{5}{*}{$\begin{array}{l}209.1 \\
\pm 11.4\end{array}$} & 33.4 & \multirow{5}{*}{$\begin{array}{l}469.7 \\
\pm 57.1\end{array}$} \\
\hline & 16 & 41.6 & & -15.6 & & \begin{tabular}{|l|}
35.3 \\
\end{tabular} & \\
\hline & 8 & 46.4 & & -13.8 & & 36.5 & \\
\hline & 4 & 50.7 & & -12.2 & & \begin{tabular}{|l|}
37.3 \\
\end{tabular} & \\
\hline & 2 & 54.2 & & -10.5 & & \begin{tabular}{|l|}
38.0 \\
\end{tabular} & \\
\hline
\end{tabular}

acteristic temperature $T_{p}$ (determined as the peak temperature) were evaluated from linear fits of the Kissinger plots for all phase transitions. The results are summarized in Table.

It was revealed that the apparent activation energy for the I-N and N-SmC (if it is present) transitions is relatively high for all LC samples. The estimated apparent activation energy for the crystallization transitions is significantly lower for all LC samples and it is the lowest for the pure banana-shaped compound. Thus crystallization is the thermally most activated process in all examined samples.

The influence of different types of magnetic particles on the phase transitions was also tested by DSC measurements. The DSC curves obtained upon heating are shown in Fig. 3. The sensitivity of phase transitions on the addition of magnetite nanoparticles of different morphologies varies depending on the $\mathrm{LC}$ compound.

Whereas magnetic particles influence the phase transitions in the rod-shaped liquid crystal very slightly, in the mixture they cause a small shift in the transition temperatures and a broadening of the melting $(\mathrm{Cr}-\mathrm{N})$ transition peak. Doping with the magnetic particles caused the most significant changes in the melting transition of the banana-shaped liquid crystal.

The melting transition has the highest sensitivity on the addition of magnetic particles because this phase transition has the lowest apparent activation energy. Moreover, as the apparent activation energy of the crystallization depends on the molecular shape of liquid crystals, one concludes that the lower is the activation energy the higher is the influence of the magnetic nanoparticles on the melting temperature, as can be seen in Fig. 3a for the pure banana-shaped LC sample.

\section{Conclusions}

Our results obtained from the DSC study for the mixture of bent-core liquid crystal with $50 \mathrm{wt} \%$ rod-shaped compound revealed that the nematic to smectic transition falls below $40^{\circ} \mathrm{C}$ and the crystallization temperature is shifted to sub-ambient temperature. The kinetics of phase transitions in studied liquid crystal samples showed that the crystallization transition has the lowest apparent activation energy in all studied samples of liquid crystals. The most significant influence of the magnetic particle doping was observed for the melting process in the pure banana-shaped liquid crystal.

\section{Acknowledgments}

This work was supported by the projects Nos. 26220120021 and 26110230097 provided in the frame of Structural Funds of the European Union, by the Slovak Academy of Sciences - VEGA 2/0045/14 and 2/0041/12, by Slovak Research and Development Agency - contract No. APVV-0171-10 and by M-era.Net project MACOSYS (OTKA NN110672).

\section{References}

[1] J. Harden, B. Mbanga, N. Éber, K. Fodor-Csorba, S. Sprunt, J.T. Gleeson, A. Jákli, Phys. Rev. Letters 97, 157802 (2006).

[2] G. Pelzl, S. Diele, W. Weissflog, Adv. Mater. 11, 707 (1999).

[3] T. Ostapenko, D.B. Wiant, S.N. Sprunt, A. Jákli, J.T. Gleeson, Phys. Rev. Lett. 101, 247801 (2008).

[4] G.G. Nair, C.A. Bailey, S. Taushanoff, K. FodorCsorba, A. Vajda, Z. Varga, A. Bóta, A. Jákli, Adv. Mater. 20, 3138 (2008).

[5] Á. Buka, N. Éber, K. Fodor-Csorba, A. Jákli, P. Salamon, Phase Trans. 85, 872 (2012).

[6] P. Salamon, N. Éber, Á. Buka, J.T. Gleeson, S. Sprunt, A. Jákli, Phys. Rev. E 81, 031711 (2010).

[7] P. Kopčanský, N. Tomašovičová, M. Koneracká, V. Závišová, M. Timko, M. Hnatič, N. Éber, T. TóthKatona, J. Jadzyn, J. Honkonen, E. Beaugnon, X. Chaud, IEEE Trans. Magn. 47, 4409 (2011).

[8] Z. Mitróová, N. Tomašovičová, M. Timko, M. Koneracká, J. Kováč, J. Jadzyn, I. Vávra, N. Éber, T. TóthKatona, E. Beaugnon, X. Chaud, P. Kopčanský, New J. Chem.35, 1260 (2011).

[9] P. van Mourik, B. Norder, S.J. Picken, Liquid Crystals 39, 493 (2012). 